\title{
Overview and progress of Chinese geographical human settlement research
}

\author{
MA Renfeng ${ }^{1,2}$, WANG Tengfei ${ }^{2}$, ${ }^{*}$ ZHANG Wenzhong ${ }^{1}$, YU Jianhui ${ }^{1}$, WANG Dai ${ }^{1}$, \\ CHEN Li ${ }^{3}$, JIANG Yanpeng ${ }^{4}$, FENG Gequn ${ }^{2}$
}

1. Key Laboratory of Regional Sustainable Development Modeling, Institute of Geographic Sciences and Natural Resources Research, CAS, Beijing 100101, China;

2. Department of Geography, Ningbo University, Ningbo 315211, Zhejiang, China;

3. College of Arts and Sciences, Beijing Union University, Beijing 100191, China;

4. College of Asia and the Pacific, The Australian National University, Canberra ACT 0200, Australia

\begin{abstract}
Increasing Chinese urbanization and industrialization has prompted greater attention to the study of human settlement and the human-land relationship in the fields of geography, architecture, and urban planning. We used bibliometric methods and statistical software to review 180 articles on human settlement in 16 Chinese geographical journals. We found that Chinese geographical human settlement research is characterized by the following: (1) Most research focuses on human settlement extension, valuation indicators, models for urban and rural settlements, theoretical exploration and the planning practices of single-factor, human settlement and complex, geographical livability in macro-scale, urban settlement differentiation and ideal patterns in medium scale, the comprehensive evaluation of settlement environment, and the planning of community units in micro-scale, community settlements; socio-cultural investigation and warnings about advancing human settlement. (2) No progress has been made in synthesizing and integrating method systems. PSR models and DPSIR models are used for targeting mechanisms, while the standard settlement evaluation system was composed of physical \& economic indicators by questionnaire surveys. On the other hand, spatial clustering based on GIS has been a frequent focus in recent years. Pioneering research on human settlement and theoretical systems within the context of China's urbanization and industrialization will provide guidance on the sustainability of Chinese cities and regions. The following five aspects require greater attention: (1) Natural suitability research on human settlement, and a survey of human settlement demands to reflect the range of different demands concerning ecologically suitable settlements in urban environments, the corresponding valuation indicators, systems, and evolution, and the impact of the residents' socio-economic attributes. (2) Spatial-temporal evaluation and sustainability research on urban and rural human settlement at various scales, focusing on evolution and spatial differen-
\end{abstract}

Received: 2016-03-22 Accepted: 2016-05-12

Foundation: National Natural Science Foundation of China, No.41230632, No.41301110, No.41501119; Zhejiang Provincial Natural Science Foundation of China, No.LY16D010008, No.Y14D010007

Author: Ma Renfeng (1979-), Postdoctor and Associate Professor, specialized in human settlement, cultural \& creative industry, maritime economy in the Yangtze River Delta. E-mail: marfxf@126.com

"Corresponding author: Zhang Wenzhong (1966-), PhD and Professor, specialized in economic location theory, livable city, human settlement and transformation of resource-based city. E-mail: zhangwz@igsnrr.ac.cn 
tiation at various scales such as city clusters and comparisons between cities, within the cities and communities. (3) Development of theory and technology for human settlement evolution research, including detection technology and methods, data mining measures, and forecasting and emulation of regional and urban human settlement evolution processes, mechanisms and patterns. (4) Research on the control of human settlement that focuses on optimization, patterns, and policies for effective management and development. (5) Estimating the human settlement system service value and establishing suitable human settlement systems, including social, economic, cultural and ecological service values.

Keywords: city and countryside; region; human settlement quality; urbanization and industrialization; human settlement evolution and control

\section{Introduction}

The past three decades have seen the unprecedented growth of China's economy and a corresponding increase in industrialization and urbanization which has resulted in the over-consumption of natural resources and the deterioration of the environment, ecological systems, and human settlements (Chen et al., 2012). With urbanization and industrialization looking to continue this trend over the next 30 years (Fan et al., 2013), the resulting negative effects on the quality of life in human settlements threaten its sustainability.

An interdisciplinary science, human settlement research involves geography, environics, ecology, urban planning, architecture, and sociology (Wu, 2001). The geographical approach currently focuses on the assessment of human settlement, ideal patterns of human settlement, residential space, risks and sustainability, and the social attributes of human settlement (Li et $a l ., 2010$ ), as well as generalized human settlement, architectural space and organization, the residential environment, infrastructure design in urban planning and subject perspective in architecture (Wu, 2001; Zhang, 2013). In summary, geography, urban planning, and related disciplines cover a range of topics and methodologies when engaging in human settlement research. However, given the urgency of the problems faced by human settlement due to rapid urbanization, the field of human settlement research needs to further investigate and develop areas which advance human-land relationship theory, practical spatial planning, and quality of life.

\section{Characteristics and core authors}

\subsection{Characteristics}

1) Research is characterized by an early start, slow development, and long-standing stagnation. The earliest published paper we could find was Residential geography in Xikang Province (Yan, 1939), establishing the early study of human settlement by Chinese geographers. The subsequent rate of publication, however, was sluggish. Bibliometric analysis shows that research on human settlement went through two phases: The first phase is prior to 2006 when few scholars worked on human settlement and those that did mainly focused on living conditions and livable city dimensions (Wang et al., 2003; Zhang et al., 2005); the second phase is post-2007, starting with three articles about human settlement which were published in Acta Geographica Sinica and Scientia Geographica Sinica (Xiong et al., 2007; Feng et al., 2007; Zhang, 2007) and the first research project on human settlement named The Evolution 
of the Rural Settlement System and Optimization of Inhabitable Environment in Jianghan Plain was sponsored by the Geography Department of National Natural Science Foundation of China in 2007.

2) There were few high quality research findings and slow growth in the field. The publications in Acta Geographica Sinica, Scientia Geographica Sinica, and Geographical Research account for $16.02 \%$ of the total literature review, mainly in Scientia Geographica Sinica, and 3 out of 10 published papers in Acta Geographica Sinica appeared in 1939. Economic Geography and China Population Resources and Environment are the top two geographical journals in China which have published most of the papers on this topic. Compared with urban planning journals which focused on rural and urban settlement (Liu, 2011; Liu et al., 2011) and general human settlement research (Wu, 2011) after 2000, prominent geographical journals were late to publish articles on human settlement (Table 1). Furthermore, the publication rate in high-level journals significantly lags behind other disciplines, suggesting a need to improve the quality of research on human settlement conducted in the field of geography.

3) Research emphasizes regional empirical analysis and exhibits a lack of theoretical innovation. Bibliometric analysis (Table 1) reveals that while the comprehensive study of human settlement receives increasing attention, there is less research related to planning or developmental strategy than there are empirical studies. Topics which have recently received greater attention include the supply and demand of human settlement elements (Wu et al., 2013; Chen, 2013), urban public security (Li et al., 2013), and natural suitability (Feng et al., 2008), however, other areas have been neglected, such as the damage to natural elements

Table 1 The number of articles related to "human settlement" in 16 geographical journals in China

\begin{tabular}{|c|c|c|}
\hline Journal name & Initial issue & Articles \\
\hline Acta Geographica Sinica & 1934 & 11 \\
\hline Geographical Research & 1982 & 6 \\
\hline Scientia Geographica Sinica & 1981 & 12 \\
\hline Progress in Geography & 1982 & 13 \\
\hline Human Geography & 1986 & 13 \\
\hline Economic Geography & 1981 & 25 \\
\hline World Regional Studies & 1992 & 2 \\
\hline Arid Land Geography & 1978 & 3 \\
\hline Areal Research and Development & 1982 & 13 \\
\hline Geography and Geo-Information Science & 1985 & 5 \\
\hline Yunnan Geographic Environment Research & 1990 & 17 \\
\hline Tropical Geography & 1980 & 9 \\
\hline China Population Resources and Environment & 1991 & 23 \\
\hline Resource and Environment in the Yangtze River & 1992 & 8 \\
\hline Journal of Arid Land Resources and Environment & 1987 & 19 \\
\hline Journal of Subtropical Resources and Environment & 1986 & 2 \\
\hline
\end{tabular}

Source: www.cnki.net, search method: "topic=human settlement" and "journal source=journal title", deadline 2nd June 2013. 
due to rapid urbanization and industrialization, the imbalance of social elements due to population growth and industries concentrated in eastern China as well as the differences of migration in inland China since 1978.

Empirical study of keyword frequency reveals that scholars prefer to take prefectural-level cities and large-scale areas as empirical research sites. Terms such as "provincial-level units," "Northeast China," and "Chinese outstanding livable cities" appeared 18 times in all. The next-most popular terms, in descending order, are as follows: the cities of Dalian and Nanjing and their surrounding areas 12 times in all; Beijing, cities on Jianghan plain, and the city of Guangzhou appeared 9 times, with Beijing urban areas and Jianghan plain counties referred to separately; and, finally, the provincial capital cities Changsha, Urumqi, Kunming, Xi'an, and Yinchuan appeared more than 4 times. The methods in the study which emphasized "assessment," "natural suitability," "function zoning of population," and "optimization of urban human settlement" can be summarized as follows (Figure 1): (1) The analytic hierarchy process, the principal component analysis, and the Delphi method were used to construct index systems and calculate weights. (2) The information entropy index, the variation index, the coordination index, and the coordination exponent model were commonly used to evaluate the coordination between human settlement and its economy and society. (3) The temporal dimension of human settlement was assessed by fuzzy mathematics, multi-objective linear weighting, logistic regression and the nerve net based on panel data. (4) Spatial analysis in GIS and cluster analysis were combined with cross-section data to quantitatively evaluate the spatial differentiation of human settlements in province, city, and county dimensions. Our research showed that while empirical studies of major cities is a main trend, there is an urgent need to improve practical planning through the application of the rule and regulation theory of human settlement.

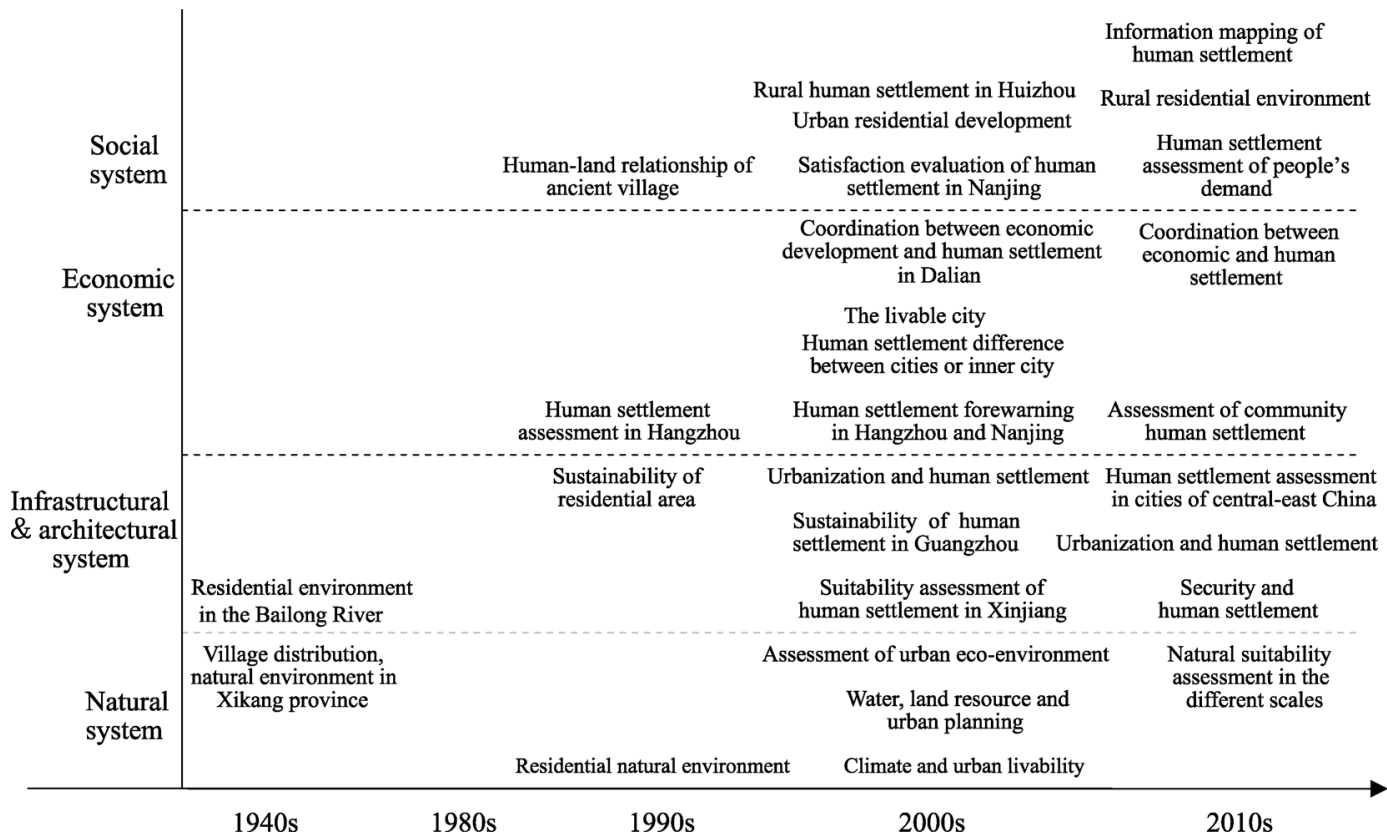

Figure 1 Distribution of the time of appearance of research topics related to human settlement research by Chinese geographical journals 


\subsection{Core authors}

1) Table 2 outlines the top six institutional affiliations of leading authors as well as changes in affiliation. Before 2000, only a small number of institutions produced research on human settlement. After 2000, the Institute of Geographic Sciences and Natural Resources Research (Chinese Academy of Sciences), Liaoning Normal University, and Nanjing University were the top sources of articles on human settlement research.

Table 2 Changes of the affiliation of the most prolific authors on human settlements (top 6)

\begin{tabular}{|c|c|c|c|}
\hline \multicolumn{2}{|r|}{ 1990-1999 } & \multicolumn{2}{|r|}{ 2000-2012 } \\
\hline Production & Institutions & Production & Institutions \\
\hline 2 & Peking University & 17 & $\begin{array}{l}\text { Institute of Geographic Sciences and Natural } \\
\text { Resources Research (Chinese Academy of } \\
\text { Sciences) }\end{array}$ \\
\hline 2 & $\begin{array}{l}\text { Ministry of Housing and Urban- } \\
\text { Rural Development of China }\end{array}$ & 16 & Liaoning Normal University \\
\hline 1 & Zhejiang University & 10 & Nanjing University \\
\hline 1 & Hengyang Normal College & 7 & Shaanxi Normal University \\
\hline & & 5 & $\begin{array}{l}\text { Fujian Normal University, Central China } \\
\text { Normal University, Nanjing Institute of } \\
\text { Geography\& Limnology (Chinese Academy } \\
\text { of Sciences) }\end{array}$ \\
\hline & & 4 & Hengyang Normal College \\
\hline
\end{tabular}

2) Based on the algorithm of core authors, the $\mathrm{M}_{2000-2012}$ we calculated was 2.12 by putting the $\mathrm{N}_{\max }=8$ into the algorithm and rounding it to 3 . Hence, we defined any author who produced more than 3 articles as a core author (Table 3). The core authors, a total of 9 from 2000 to 2012 , account for $5.29 \%$ of the total authors while their publications amount to $25.53 \%$ of the total publications. The results show an increase in the number of core scholars and articles, indicating a more general increase in scholarship on human settlement within the field of Chinese geography.

Table 3 The core authors and the number of their articles related to human settlements

\begin{tabular}{cl}
\hline Period & \multicolumn{1}{c}{ The most prolific authors/TA } \\
\hline $1990-1999$ & Nie Meisheng (Ministry of Housing and Urban-Rural Development of China/2) \\
2000-2012 & $\begin{array}{l}\text { Li Xueming (Nanjing Normal University, Liaoning Normal University/22), Zeng Juxin (Central } \\
\text { China Normal University/6), Feng Zhiming (Chinese Academy of Sciences/5), Zhang Wenzhong } \\
\text { (Chinese Academy of Sciences/4), Li Bohua (Central China Normal University, Hengyang Normal } \\
\text { College/5), Peng Buzhuo (Nanjing University/4), Qi Xinhua (Sun Yat-sen University/4) }\end{array}$ \\
\hline
\end{tabular}

3) By data retrieval performed within the Chinese Science Citation Database, we investigated the citations of each paper. We found that 73 of the 100 most highly cited articles were published in journals of architecture, urban planning, and urban studies. The most highly cited article was "On the Methodological Thinking of Building the Science of Human Settlement Environment," published in the 6th issue of City Planning View in 1999. Interestingly, the bibliometrics reveal that the top 15 cited articles of human settlement in geographical journals were all produced by the core authors or their team members. 


\section{Research trends}

Most research focuses on human settlement extension, valuation indicators, models for urban and rural settlements, theoretical exploration and the planning practices of single-factor, human settlement and complex, geographical livability in macro-scale, urban settlement differentiation and ideal patterns in medium scale, the comprehensive evaluation of settlement environment, and the planning of community units in micro-scale, community settlements; socio-cultural investigation and warnings about advancing human settlement.

\subsection{Natural suitability}

In recent years, the natural environment suitability for human settlement in China has been applied to residential evaluation and environmental assessment, and some standard evaluation systems have been established based on RS and GIS.

\subsubsection{Natural suitability and elements}

The natural suitability of human settlement can be defined as the degree to which there is a suitable combination of the following elements: climate, terrain, water and soil resources, hydrothermal conditions, atmosphere, land use, land cover, and natural disasters, all of which have an impact on human settlement (Feng et al., 2008; Min et al., 2012; Zhang et al., 2013).

For village or city clusters with large populations, natural suitability research could provide theoretical guidance and realistic values for the scale and location of settlements in provincial, national, and global dimensions. However, the homogenization of the natural environment in the inner city due to high density infrastructure, modern construction, and highly intensive human activities applied to the land surface makes it less of a focus for current research.

\subsubsection{Research field}

The natural environment is the very foundation of human settlement formation and development, and researchers are paying increasing attention to the impact of terrain, soil, meteorology, atmospheric environment, and acoustical environment on human settlement (Feng et al., 2007). Human settlement suitability research analyzes how regional natural elements affect human settlement and explores the dominant element on ArcGIS. Studies have focused on the following: (1) The impact of climate as a significant core element for a livable city in the human settlement system. Examples were provided by empirical research articles on Kunming, Chuxiong and 35 other cities, Guizhou province, and even Chinese rural areas and the 1-km or 5-km grid (Zhang et al., 1991; Liu, 1999; Li et al., 2003; Tang et al., 2008; He et al., 2008), which not only verified the importance of climate in human settlement, but also showed that climate suitability decreased from southeast to northwest China accompanying the changes from continental plateau to mountains to hills and to plains. Furthermore, there were striking differences in the degree to which climate was assessed as comfortable in different parts of China, with the most comfortable climate areas distributed in the Southeast Hilly Regions and the Yunnan-Guizhou Plateau, and the most uncomfortable areas distributed in paramos areas such as the Tibetan Plateau and the Tianshan Mountains. (2) Multi-natural elements have been adopted to comprehensively evaluate regional natural 
suitability and human settlement restrictions with ArcGIS raster data. Research on Yunnan province, the Inner Mongolia Autonomous Region, Shaanxi province, the central Shaanxi plain to the city of Tianshui, southern Xinjiang Uygur Autonomous Region, the city of Wanzhou, the city of Zunyi, and the whole of China showed that topographic relief, the temperature-humidity index, the hydrological index, and the land cover index worked together to affect the natural suitability of human settlement; among these elements, elevation, slope, and water and farmland resources were leading factors in mountainous and hilly areas (Shen et al., 2006; Zhang et al., 2012). In plains, plateaus, and basins, however, water resources and climate were the leading factors (Feng et al., 2007; Liu et al., 2012). (3) Natural suitability has played a fundamental role in population distribution and its optimization. The National Population and Family Planning Commission of China subsidized Feng's research team which found that there is a notable positive correlation between population distribution and the index of natural suitability in China (Liu et al., 2012; Feng et al., 2012). With the influence of human activities, the natural suitability of human settlement in inner cities often encompassed greening, hydrology, and atmosphere as important parameters, while seldom took natural factors into account because of a lack of data at present.

\subsubsection{Methodology}

Natural suitability assessment methodology generally selected indicators such as terrain, climate, hydrology, land cover, and natural disasters, and used weighted evaluation by raster data (Feng et al., 2008; Min et al., 2012). As Figure 2 depicts, the research flow chart of natural suitability was composed of choosing elements and constructing a raster data base, selecting measure methods and data sources, building evaluation models, identifying the threshold of each typology, and analyzing optimized patterns.

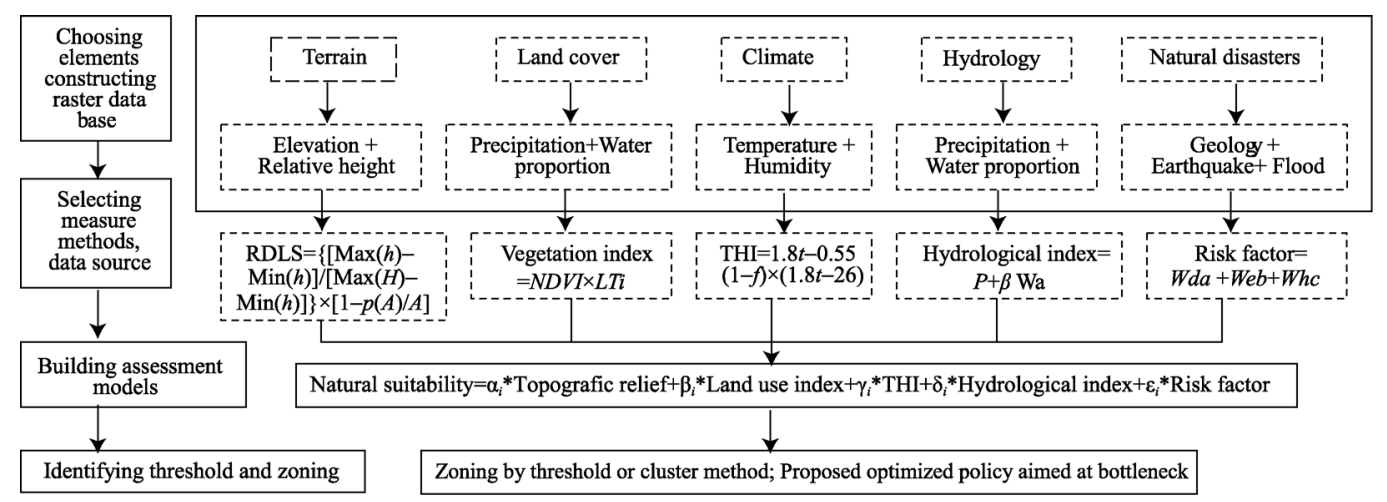

Figure 2 Methods of human settlement natural environment suitability evaluation

Notes: The meaning of h, H, L, t, P, W $\alpha$, Wda, Web, Whc see Feng Z, Tang Y, Yang Y et al. (2008) and Min J, Liu C, Li Y (2012).

\subsection{Human settlement assessment}

Human settlement assessment which aimed to construct a comprehensive assessment system of living environment for cities, village, and prefecture-level administrative units from four aspects: supporting conditions of housing conditions, ecological environment, public facilities and social economy. The goal of human settlement assessment which aimed to achieve 
sustainable development and residents' demands usually described the status and trends of regional human settlement.

\subsubsection{Human settlement assessment and research paradigms}

Human settlement assessment which aimed to achieve sustainable development and residents' demands usually described the status and trends of regional human settlement. Differences in purpose, content, and methodology produce the two assessment paradigms presented in Figure 3: (1) One model aimed to evaluate the status of sustainable development or the evolution of residents' demands for human settlement. The vertical assessment of human settlement mostly adopted a multiple quantitative method to analyze statistical information on economic, societal, environmental, or questionnaire data (Ye et al., 2003; Zhang et al., 2006; Chen, 2013). (2) The other model aimed to evaluate the superiority of an area in comparison with the evaluation of the solutions and contradictions of human settlement optimization. The lateral comparative research mostly took advantage of economic, societal, and environmental statistics to assess the spatial differentiation of human settlements in a year or every three years (Liu et al., 2005; Li et al., 2011; Yang et al., 2012; Li et al., 2012). In addition, several scholars attempted to evaluate the evolution and differentiated trends of regional human settlement in spatial-temporal dimensions. Both paradigms made use of data sources such as sectoral statistical data, subject investigation, questionnaire surveys, satisfaction and happiness indexes, and the index weighted sum method, etc.

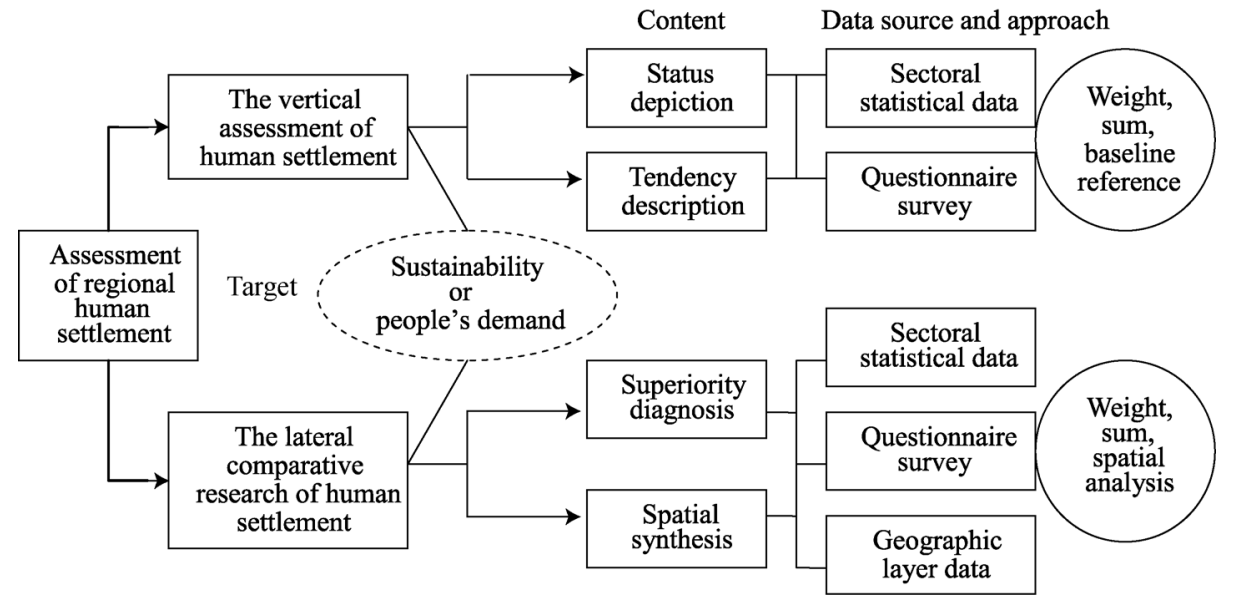

Figure 3 Paradigms of human settlement evaluation

\subsubsection{Research field}

Regional human settlement assessment largely selected urban or rural areas as a study subject with few in the rural-urban fringe (Qi et al., 2008). The sub-discipline of geography which was the most highly associated with human settlement, settlement geography, was devoted to research in urban and rural areas. Geographical scholars paid close attention to assessment, spatial differentiation of developmental degree, and planning and constructing in urban and rural areas (Li et al., 2010; Zhang et al., 2013).

Urban human settlement assessment is focused on its development level, spatial differentiation, and the driving factors of human settlement in inner cities. The areas receiving the greatest amount of attention include metropolises such as Dalian, Beijing, Guangzhou, 
Shanghai, Hangzhou, Nanjing, Xiamen, Huhhot, and Xi'an (Li et al., 1999; Li et al., 2004; Zhang et al., 2005), and small cities such as Hengyang and Dandong (Li et al., 2008; Hu et al., 2011). The indexes were chosen from the elemental and detailed index of good or soft human settlement which can be summarized as describing status, reflecting trends, and weighting direction of three types (Zhang et al., 2013). The data was collected from remote sensing, statistical yearbooks, interviews, microcosmic information based on GPS or Wi-Fi technology, and used AHP, Delphi, DPSIR and comparative methods to normalize and weight, and integrated indexes by linear weight sum and fuzzy hierarchical clustering (Liu et al., 2014). Such empirical articles indicated the following: (1) On the whole, urban human settlements developed well and the good environment was superior to the soft environment. (2) Residents' demands for human settlement diversified and increased with each passing day. (3) There was a spatial imbalance of human settlement in China which reflected a wide gap between developed and developing regions (Li et al., 2012; Chen, 2013).

Rural human settlement assessment in Chinese geographical circles has shown great interest in the characteristics of human settlement in ancient times and the optimization of human settlement since the time of new construction in rural areas. The former research area concentrated on human settlements such as the ancient villages of Wuzhen town and Huizhou (Liu, 1998; Lu et al., 2004), the characteristics of longevity in settlements such as the city of Zhongxiang, and the satisfaction with human settlement in underdeveloped areas (Ma et al., 2012; Li et al., 2012). The latter research looks at influencing factors of human settlement in Beijing's suburban countryside with a new era of countryside construction and the impact of migrant workers on living environment (Zhou et al., 2011; Yang et al., 2012). Altogether, rural human settlement assessment focused on the essence of human settlement, the relationship between agricultural and living environment, and farmers' demands. However, although rural settlement assessment strategy did not differ distinctively from that of urban human settlement assessment, the former only obtained data by questionnaire or interview due to a shortage of statistical data.

A major area of human settlement research, comparison research analyzes the differences between human settlements in cities, counties, and provinces (Zhou et al., 2004; Liu et al., 2005; Wen et al., 2007). Livability analysis of 50 Chinese cities found that the livable city possessed in all cases high levels of economic development potential, public security, ecological environment, and accessibility, while differences arose from economic development, infrastructure, and public service (Li et al., 2007; Li et al., 2008). Other literature focused on the use of principal component analysis and cluster analysis in Jiangsu and Anhui provinces, and suggested that economic, ecosystemic, and employment factors were the primary causes of differences between inner provincial cities (Liu et al., 2005; Wen et al., 2007).

Urban and rural human settlement assessment and analysis has been shown to focus on the features, status, tendencies, and merits of cities and villages; and urban-rural human assessment planning, while the areas requiring greater care and attention include microcosmic data acquisition, index weighting, model formulation, and even unsatisfactory conclusions caused by the selected scale of study area.

3.2.3 Data sources, indicators, and models

Contemporary time-space compression, caused by advanced information technology and 
globalization, significantly affects modern daily life and produces complex and cross-dimensional demands for human settlement. Accordingly, human settlement assessment needs to take into account both local residents and the transient population which includes business people, tourists, and casual workers, in order to produce accurate data and build comprehensive assessment models. That is to say, critical to the process of human settlement assessment are the acquisition and management of data, the selection of indicators, and the design of models.

Human settlement assessment data has been gathered from multiple sources: (1) natural environmental, economic, societal, and infrastructural data was extracted from multiple remote sensing sources and National Geographic Information Data. (2) Economic data was also excerpted from statistical bureau or industry sector governmental information. (3) Social data was collected from population census-taking, cultural surveys, and city crime alarm data. (4) Infrastructural data was extracted from information on communication networks, green spaces, public gardens, educational services, and medical facilities provided by thematic maps and digital city systems. The data consisted of macro-scale statistical information and spatial data provided by national thematic censuses, but lacked behavioral records and needs surveys which are a principal element of human settlement. Consequently, current research efforts are increasingly focused on acquiring large samples of people's demand and behavior data through diary, GPS and LBS technology, and questionnaire surveys (Zhang et al., 2006).

The human settlement assessment indicator system not only objectively measured the natural environment, economy, society, and infrastructure for living, working, and recreation, but also explored satisfaction and the availability of human settlement potential for psycho-social growth and satisfaction among different populations. The natural environment was described by terrain, land cover, climate, hydrology, and natural disasters; the social environment was described by indicators of social structure, neighborhood relations, the sense of belonging and identity, public security, the jobless rate, all of which could be summarized as a reflection of social diversity (Chen, 2013); the economic environment was described by economic growth, economic quality, regional economic structure indicators; the infrastructural environment indicators were related to the quantity and quality of service facilities available in daily life. The other researchers could go into more detai indicators becomes available.

Current research has adopted factors analysis, fuzzy mathematics, and a nerve net assessment model, but has disregarded spatial variability. Consequently, there is a growing need to incorporate spatial elements into assessment models in order to explain characteristics in spatial-temporal dimensions by way of geographically weighted regression, spatial clusters, and geographical detectors.

\subsection{Human settlement evolution}

Human settlement evolution research has been vital for developing a better understanding of settlement problems. Zhang et al. have reviewed the influencing factors, analytic theories and framework of human settlement evolution (Zhang et al., 2013). We focus here in particular on the relationship between urbanization, industrialization, and human settlement evolution, and on the empirical study of human settlement evolution. 
3.3.1 The relationship between human settlement evolution, economic growth, and urbanization

Urbanization and industrialization have been themes of the past 40 years of research and will continue into the future. They have also brought about a recognition of negative environmental impacts. Chinese geographical research has made great strides in investigating the relationship between human settlement evolution, economic growth, and urbanization, mainly focusing on correlation and phases: (1) In research on the links between urbanization and human settlement evolution, for example, the articles quantitatively evaluating evolution under urbanization by methods of principal component analysis coordination index and fuzzy mathematics in the city of Dalian and the district of Ganjingzi both concluded that human settlement and urbanization had positive correlation as well as high coordination (Li et al., 2004; Li et al., 2008). Moreover, several academic papers discussed the impact of the greenhouse effect from urbanization on urban human settlement evolution (Zhao et al., 2010). (2) Studies based on fuzzy mathematics analyzed the relationship between economic growth and human settlement in the cities of Dalian, Shenzhen, and Changsha (Xiong et al., 2007; Qi et al., 2008; Li et al., 2005; Huang et al., 2012), and found that human settlement was closely tied to economic development, and that economic growth helped improve human settlement in general but was characterized by a lack of stability. In recent years, scholars have increasingly put the spotlight on human settlement evolution in metropolis fringe and peri-urban areas (Huang et al., 2012; Qi et al., 2010).

Overall, human settlement evolution was demonstrated to be intricately correlated with urbanization and industrialization, which was characterized by two aspects: firstly, human settlement evolution and urbanization had notable positive correlation, and revealed the tendency of coordination to be low-high-low-high; secondly, the model of the relationship between economic development and human settlement was indistinct, based on a few empirical articles which preliminarily discovered both coordination and uncertainty between them. Nonetheless, as a key dynamic factor of human settlement evolution, economic development will improve the quality of human settlement if it also reduces environmental pollution and farmland encroachment.

\subsubsection{Research field}

Studies on human settlement evolution are an important part of human settlement assessment, driving factor exploration, forewarning, and control. Up until now, empirical studies have concentrated on the following: (1) The comparative study of human settlement evolution of one city in different phases or various urban centers in the same phase. For example, Li et al. used subjective and objective methods and models of human settlement quality to study the evolution of the city of Nanjing (Li et al., 2005); Jin figured out the competitive power of 14 cities in Liaoning Province in 1994, 1999, 2004, and 2009 based on principal component analysis (Jin et al., 2011); adopting a variation index and coordination index to measure human settlement quality in the Changsha-Zhuzhou-Xiangtan urban agglomeration from 1991 to 2008, Li found that the education and technology system, economic system, and residential living system were most responsible for widening gap in the quality of human settlement between different cities (Li et al., 2011). (2) The exploration of the phases and drivers of human settlement evolution in metropolises or metropolitan fringes (Qi et al., 
2010). For example, one study used GIS technology and the Verhulst logistic equation to dissect human settlement evolution on the fringe of the city of Guangzhou; the article concluded that the dynamics of human settlement evolution could be classified into a macro-scale dynamic (urbanization, globalization, science and technology, and market systems), a governmental dynamic (household registry reform, land reform, housing reform, urban-rural development policy, and major investment projects), and an interaction dynamic with the city (core area impetus, rural impetus, and fringe attractions).

Existing Chinese research comparing the human settlement evolution of one city in different phases or various cities in a common phase mostly selected Nanjing, Dalian, Guangzhou, or the Changsha-Zhuzhou-Xiangtan urban agglomeration as the areas of study, but lacked the systematic exploration of influencing factors, dynamics, spatial organization, mechanisms and so on. Consequently, there is an urgent need for the theoretical logic of human settlement evolution that includes an integrated approach and data source (Zhang et al., 2013).

\subsubsection{Driving forces of people's demands for human settlement in post-industrial society}

With several metropolises and urban agglomerations having entered into a post-industrial period, the demands of urban and rural residents are pluralistic. Geographical researchers have, therefore, laid special stress on surveys of residents' perceptions, satisfaction levels, and demands. A city could be deemed to have advanced to post-industrial society when the needs of different populations lead to the evolution of the settlement. Current studies emphasize the importance of quality of life in urban settlement development (Hou et al., 2004; Wu et al., 2013). For instance, scholars analyzed the contradictions between rich habitat and environmental resources on the one hand and a shortage of entrepreneurship on the other in the city of Suzhou, while another article discussed the demand for good health and other elements deemed necessary by different people in the city of Guangzhou, and found the following: (1) only people in good health could enjoy the convenience, amenities, and security provided by a livable city. (2) Interviewees raise different demands for 10 elements of recreation while having 22 elements of livelihood in common; time at home/away from work and income were extremely influential on different groups' demands. Li proposed the concepts of human settlements' attraction and human settlements' gravity field (Li et al., 2012), then constructed an index system for the environment's satisfaction of a human settlement community and calculated the gravity field strength of 184 communities in the city of Dalian based on a gravitational potential energy model, and discovered that: (1) The gravitational potential energy of the human settlement community differentiated in space, distributed along a southwest-northeast belt, and diminished concentrically from the central square, Jinhui market on Xi'an road, to the peripheral areas; and (2) the supply and demand of the human settlement community was proportional to its gravitational potential energy, but inversely proportional to the distance between the community and the center of gravitational potential energy.

In conclusion, subjective demands for human settlement cannot be accounted for by the mere consideration of urban development phases like the study which valued entrepreneurship in Suzhou and Guangzhou, but require the consideration of the material basis of urban human settlement such as the study which combined subjective and objective elements to 
design a satisfaction gravity field and measure spatial differentiation in Dalian. Surveys on the drivers of different groups' demands for human settlement should take the availability of facilities for native and transient population and the diversity of urban society against the background of urban-rural integration into account to produce a comprehensive understanding of the driving forces and different demands of human settlement evolution.

\section{Overview and prospect}

\subsection{Contributions and deficiencies of human settlement research in the field of Chinese geography}

Chinese geographers have demonstrated a persistent interest in human settlement research and the development and application of methods distinct from general architectonics. In the past 10 years, the proliferation of geographical research on human settlement has contrasted with the shortage of research in general architectonics. The study of human settlement marks a breakthrough from macro to micro scale as well as from economic to social development from a geographical perspective which has a brilliant future determined by both the characteristics and objects of geography. Nevertheless, Chinese research on human settlement started late, with a current focus on natural suitability, the combined urban and rural human settlement assessment, the relationship between human settlement, urbanization, and economic growth, different groups' demands for human settlement, and the driving forces of human settlement. Although current research uses an index system, it lacks consecutive data, the first-hand data of questionnaire surveys, and remote sensing data; furthermore, while inter-city and inter-county research has gradually been extended to a provincial scale, it has neglected to conduct overall scales exploration and temporal series empirical research. Also, less attention has been paid to influencing factors, law and mechanism research, and the correlation between social elements and human settlement, although there has been some study of relationship between urbanization, economic growth, and human settlement.

Geographical society takes "pattern, process, principle" as its research object to understand the interactive relationship between land and human activities, which was a core contribution to human settlement research in the field of geography. However, in the light of correlative investigations, we find that geography places particular emphasis on the "pattern" in human settlement research, while the "pattern" studies focus on cities and inner cities in particular as their key perspectives. Human settlement research from a geographical perspective is at an initial stage, and has not formed a systematic approach and logic to theoretical exploration and research. Hence, geographical scholars should grasp the opportunities provided by rapid urbanization and rural development, and focus on urban or rural human settlement description, human settlement problem identification, comprehensive human settlement theory-index-model assessment in spatial-temporal dimensions, human settlement elements-force-pattern evolution to carry out exploration and research on the frontiers of human settlement.

\subsection{Human settlement research and new breakthroughs in Chinese geography circles}

Compared to international research, significant Chinese human settlement research can be carried out in the following fields (Zhang et al., 2013): (1) Interdisciplinary and comprehen- 
sive research can be taken as an approach to promote cross-disciplinary integration research and highlight geographical characteristics. As human settlement research shows its unique systematicness and comprehensiveness, it is necessary for multidisciplinary and multiple-stranded approaches to integrate innovation. Therefore, geography needs to adequately draw lessons from relevant theory and methodology in ecology, urban planning, sociology, and architecture to make a breakthrough at the methodological bottleneck and to build human settlement methodological-theoretical systems with geographical characteristics. (2) Research should center on geographical multi-source data and triangle verification to build a human settlement research database, and explore combining macro-data like remote sensing and yearbooks with micro-data from questionnaire surveys, GPS positioning, establish data platforms, accumulate monitoring data to upgrade academic efficiency and quality. (3) Research should focus on the course of human settlement evolution in typical regions, promoting the simulation of human settlement evolution, intelligent expert analysis, and the construction of decision-making platforms on different scales. The comprehensive and integrated research of human settlements does not only need macro-study on a large scale, but also typical cases in micro-scale. On the one hand, human settlement research highlights how the large scale distinctly mirrors a development mode of human settlement in different areas, which could provide both policy support and the sound development of human settlement and management experience for other areas. On the other hand, the demonstrated effect and rich experience of a typical case study are beneficial to forecasting and simulating human settlement evolution in different areas.

The characteristics and research objects of geography point towards a promising future in human settlement research. At present, geography stresses natural suitability assessment theory and application, the index system and models measuring human settlements in spatial-temporal dimensions, and simultaneously, the exploration of human settlement evolution. These are some of the ways that the study of human settlements will enhance a deeper understanding of geography and the human-land relationship, explore the "time and space compression" evolutionary mechanism, and provide information on controlling the mode of urban or rural human-land relationships. Additionally, the discipline of geography can expand and deepen the following five aspects of human settlement research: (1) It should pursue natural suitability research and demand surveys of different groups on the quality of life in human settlements, design an index system which reflects urban groups' ecological demands for their habitat, uncover individual and group differences in the supply and demand of human settlement elements, and assess the impact of residents' demands. (2) It should explore spatial-temporal assessment and the sustainability of urban or rural human settlements on different scales, expand the application area of sustainable development assessments, and deepen regional studies and development assessment criteria in geography. Namely, residents' satisfaction and the evolution and spatial differentiation of human settlement sustainability can be evaluated in inner urban agglomerations, cities at various levels, and at a community scale. Also, the quality of human settlement can be evaluated as an intermediary between human residence and urban or rural sustainable development. (3) It should explore and build human settlement evolution theory, analysis, and research routes, enrich monitoring technology and means of data mining, while also exploring forecasting and simulation processes, mechanisms, and patterns of regional and urban human settlement 
evolution to increase diagnostic strength and forewarning capacity for human settlement systems. (4) It should discuss the regulation of human settlements and propose optimal paths, modes, and policies to achieve effective management and positive development built on influencing factors, dynamic mechanisms, and patterns of human settlement. (5) It should estimate the service value of human settlement systems, create an inhabitable human settlement system that also promotes stable ecosystems in the context of climate change. A sustainable natural environment contributes to the holistic service value of human settlements which includes socio-economic value, cultural value, and ecological service value. There is clearly an important need to explore the value assessment system of human settlement control and uncover the rules of the human-land relationship.

\section{References}

Chen L, 2013. Research on spatial differences and mechanism of urban residential environment [D]. Beijing: Chinese Academy of Sciences. (in Chinese)

Chen L, Zhang W, Dang Y et al., 2012. The spatial distribution, transition and residential pattern of low-income resident in Beijing. Geographical Research, 31(4): 721-732. (in Chinese)

Fan J, Liu Y, Chen T et al., 2013. The key strategies and innovative thinking for optimization on spatial pattern of urbanization in China. Bulletin of the Chinese Academy of Sciences, 28(1): 20-27. (in Chinese)

Feng Z, Tang Y, Yang Y et al., 2007. The relief degree of land surface in China and its correlation with population distribution. Acta Geographica Sinica, 62(10): 1073-1082. (in Chinese)

Feng Z, Tang Y, Yang Y et al., 2008. Establishment and application of human settlements environment index model (HEI) based on GIS. Acta Geographica Sinica, 63(12): 1327-1336. (in Chinese)

Feng Z, Yang Y, 2012. A GIS-based study on sustainable human settlements functional division in China. Journal of Resources and Ecology, 1(4): 331-338.

He P, Li H, 2008. The meteorologic exponent analyses of people inhabit in Yunnan province Chuxiong city. Yunnan Geographical Environment Research, 20(3): 114-117. (in Chinese)

Hou A, Ju Y, Yuan Z, 2004. Importance and cultivation of entrepreneurship in urban habitat development in Suzhou. Areal Research and Development, 23(3): 86-89. (in Chinese)

$\mathrm{Hu}$ Z, Deng M, Liu P et al., 2011. Niche suitability assessment for human settlement in Hengyang based on GIS. Tropical Geography, 31(2): 211-215. (in Chinese)

Huang N, Cui S, Liu Q et al., 2012. Study on the characteristics of community human settlements in peri-urban area during urbanization: A case of Jimei District, Xiamen city. Progress in Geography, 31(6): 750-760. (in Chinese)

Jin P, Li X, Feng K, 2011. The spatial-temporal and evaluation evolvement of the urban settlement environment competitiveness of Liaoning province. Economic Geography, 31(10): 1638-1646. (in Chinese)

Li B, Liu P, Dou Y, 2012. Evolution characteristics and micro mechanism of rural human settlement in underdeveloped areas during the transition. Human Geography, 27(6): 62-67. (in Chinese)

Li B, Tan Y, Liu P, 2011. Research on evolution of human settlement spatial disparities in Chang-Zhu-Tan "3 + 5" urban agglomeration. Yunnan Geographical Environment Research, 23(3): 13-19. (in Chinese)

Li H, Xu R, Gao Z, Peng B, 2005. Early warning of the quality of human settlement in scale of Nanjing city. Economic Geography, 25(5): 658-662. (in Chinese)

Li M, Li X, 2007. Application research on quality evaluation of urban human settlements based on the BP neural network improved by GA. Economic Geography, 27(1): 99-103. (in Chinese)

Li W, Ye X, Sun Y, 1999. The assessment of urban human settlements: A case study of Hangzhou. Economic Geography, 19(2): 38-43. (in Chinese)

Li X, Liu J, 2003. Preliminary study on the fuzzy comprehensive appraisal to environment climate of the urban 
human settlement. Economic Geography, 23(5): 656-660. (in Chinese)

Li X, Jin P, 2012. Characteristics and spatial-temporal differences of urban human settlement environment in China. Scientia Geographica Sinica, 32(5): 521-529. (in Chinese)

Li X, Li J, 2010. Current research and prospect of human settlements studies in geography. Journal of Liaoning Normal University (Natural Science Edition), 33(1): 112-117. (in Chinese)

Li X, Li M, 2008. Evaluation and analysis of the major urban human settlements based on embodying self-realization deeds in China. Scientia Geographica Sinica, 28(6): 742-747. (in Chinese)

Li X, Li W, 2005. Quantitative analysis about coordinating development of environment of urban human settlements and economy in Dalian since the 1900s. Economic Geography, 25(3): 383-386. (in Chinese)

Li X, Zhang C, Zhang X et al., 2004. Quantitative research on urbanization and environment for human settlements: Take Dalian as an example. China Population Resources and Environment, 14(1): 91-96. (in Chinese)

Li Y, Zhu H, 2013. Spatial distribution and influencing mechanism of social and public security: An urban security spatial analysis based on from city crime alarm data. Geographical Research, 32(5): 870-880. (in Chinese)

Liu J, Zhang W, 2014. Review of habitat environment assessment method. Urban Studies, 21(6): 46-52. (in Chinese)

Liu P, 1998. Ancient village: The unique space of human settlement culture. Human Geography, 13(1): 35-38. (in Chinese)

Liu P, 1999. Study on the climate comfort-index of human settlement environment in rural of China. Journal of Hengyang Teachers College, 20(3): 51-54. (in Chinese)

Liu Q, Lin Z, Feng N, 2005. Evaluation on the spatial differences of urban settlement environment of Jiangsu province. Areal Research and Development, 24(5): 30-33. (in Chinese)

Liu R, Feng Z, Yang Y, 2012. Research on the spatial pattern of population agglomeration and dispersion in China. Progress in Geography, 29(10): 1171-1177. (in Chinese)

Liu Y, 2011. A statistical analysis of urban geography studies in China. Progress in Geography, 30(6): 681-690. (in Chinese)

Liu Y, Long H, Zhang X, 2011. Research progress and prospect in the disciplines of agricultural geography and rural development in China. Progress in Geography, 30(12): 1498-1505. (in Chinese)

Lu L, Ling S, Jiao H, 2004. Study on evolution process and mechanism of Huizhou ancient village. Geographical Research, 23(5): 686-674. (in Chinese)

Ma J, Zeng J, 2012. Study on longevity phenomena and human settlements in rural China: Taking Zhongxiang city as an example. Geographical Research, 31(3): 450-460. (in Chinese)

Min J, Liu C, Li Y, 2012. Nature suitability for human settlement based on GIS technology. Resource and Environment in the Yangtze River, 21(8): 1006-1012. (in Chinese)

Qi X, Cheng Y, Chen L, 2008. The evolvement rules of human settlements system on metropolis fringe: A case study of Guangzhou. Economic Geography, 25(5): 794-798. (in Chinese)

Qi X, Cheng Y, Hu X, 2010. The evolvement rules of human settlements system on metropolis fringe: A case study of Guangzhou. Acta Ecologica Sinica, 30(16): 4512-4520. (in Chinese)

Shen B, Jin Y, 2006. The research in the comprehensive evaluation to main natural factors of the residential environment of hilly ground geographic information system take Xianju county of Zhejiang province as a example. Economic Geography, 26(S): 305-311. (in Chinese)

Tang Y, Feng Z, Yang Y, 2008. Evaluation of climate suitability for human settlement in China. Resource Science, 30(5): 648-653. (in Chinese)

Wang M, Zhang X, Luan W, 2003. Structure and spatial analysis of evaluation of residential environment in Dalian city. Scientia Geographica Sinica, 23(1): 87-94. (in Chinese)

Wen Q, Fang F, 2007. Analysis of human settlement regional difference in Anhui province. Yunnan Geographical Environment Research, 19(2): 84-87. (in Chinese)

Wu L, 2001. Introduction to Science of Human Settlements. Beijing: China Architecture \& Building Press. (in 


\section{Chinese)}

Wu L, 2011. The Research Progress of the Science of Human Settlements (2001-2010). Beijing: China Architecture \& Building Press. (in Chinese)

Wu Q, Cheng J, Zhong S et al., 2013. Empirical research of urban human settlement environment elements based on the needs of different subjects: A case study of Xintang Town, Guangzhou. Geographical Research, 32(2): 307-316. (in Chinese)

Xiong Y, Zeng G, Dong L et al., 2007. Quantitative evaluation of the uncertainties in the coordinated development of urban human settlement environment and economy: Taking Changsha city as an example. Acta Geographica Sinica, 62(4): 397-406. (in Chinese)

Yan Q, 1939. Residential geography in Xikang province. Acta Geographica Sinica, 6(1): 43-58. (in Chinese)

Yang J, Li X, Li Y, 2012. Assessment on spatial differences of human settlement environment in communities based on DPSIRM model: The case of Dalian city. Geographical Research, 31(1): 135-143. (in Chinese)

Yang J, Zhao X, 2012. On impact study of the out flow of peasant workers in rural areas to improve the living environment. China Population Resources and Environment, 20(8): 22-26. (in Chinese)

Yang Y, Feng Z, 2009. The population development functional zoning in Inner Mongolia. Journal of Arid Land Resources and Environment, 23(10): 1-7. (in Chinese)

Ye C, Dong Y, 2003. Synthetic evaluation on the level of sustainable development of human settlement in Guangzhou. Tropical Geography, 23(1): 59-61. (in Chinese)

Zhang D, Ren Z, Liu Y et al., 2012. The spatial distribution pattern analysis of population in Loess Plateau region based on nature suitability for human settlement. Economic Geography, 32(11): 13-19. (in Chinese)

Zhang J, Feng Y, 1991. A study of the climate pleasantness evaluation of Guizhou province. Tourism Tribune, 6(3): 50-53. (in Chinese)

Zhang T, 2013. Design method and pattern about Sima Qian Temple in Hancheng from the perspective of human settlement science. Journal of Xi'an University of Architecture \& Technology (Natural Science Edition), 45(1): 79-85. (in Chinese)

Zhang W, 2007. Index system and method of residential environmental evaluation in inner cities. Scientia Geographica Sinica, 27(1): 17-23. (in Chinese)

Zhang W, Chen L, Yang Y, 2013. Research progress on human settlement evolution. Progress in Geography, 32(5): 710-721. (in Chinese)

Zhang W, Liu W, Meng B, 2005. On location advantage value of residential environment in the urban and suburban area in Beijing. Acta Geographica Sinica, 60(1): 115-121. (in Chinese)

Zhang W, Yin W, Zhang J et al., 2006. A Study of Livable City in China. Beijing: Social Sciences Academic Press. (in Chinese)

Zhao H, Jing Y, Liu J, 2010. Analysis of coordinated development between urbanization and environment of human settlement based on urban thermal environment: A case of Nanjing city. Yunnan Geographical Environment Research, 19(S): 203-207. (in Chinese)

Zhou K, Lin X, 2011. Characteristics and influence factors of human settlement in Beijing suburban countryside since new countryside construction. Human Geography, 26(3): 76-82. (in Chinese)

Zhou Z, Wang H, Yang D, 2004. Study and evaluation on lodgeable cities in China. China Population Resources and Environment, 14(1): 27-30. (in Chinese) 